\title{
Innovative Ecosystem of Mining Industry
}

\author{
Oleg Kalenov ${ }^{1, *}$, Sergey Kukushkin ${ }^{2}$ \\ ${ }^{1}$ Plekhanov Russian University of Economics, Academic Department of Industrial Economics, \\ 117997, Moscow, 36 Stremyanny lane, Russia \\ ${ }^{2}$ Plekhanov Russian University of Economics, Academic Department of Organizational and \\ Managerial Innovations, 117997, Moscow, 36 Stremyanny lane, Russia
}

\begin{abstract}
The mining industry belongs to the leading sectors of the global economy. However, the technologies used in it can not always be called innovative. This is due to both the specifics of the industry and the general technological lag of Russian economy. At present, it is almost impossible for individual enterprises to achieve significant success apart. In order for the process of innovative technological development to proceed more intensively, it is necessary to consider it through the prism of the ecosystem, i.e. a set of participants and the corresponding environment of this process, allowing to achieve a synergistic effect. The concept of an innovative ecosystem is based on the triple helix model, which is in turn based on a partnership between the state, science and business. They can interact effectively on the basis of technopark structures, which are a key element of the modern innovation ecosystem. The study was conducted on the basis of the Kemerovo region - a region in which a significant part of the Russian mining industry is concentrated. One of the tools for implementing the ecosystem approach to managing the development of the mining industry should be the main element of the innovation infrastructure of the Kemerovo region - the Kuzbass Technopark.
\end{abstract}

\section{Introduction}

The mining industry is the most important industry in the primary sector of the economy and includes the extraction, processing and enrichment of mineral raw materials. In the XX century, exploration of new mineral resources was active. The same can be said about the rate of extraction of raw materials. Today, mineral reserves are melting, and humanity has seriously considered replacing traditional energy resources. However, exploration and development of deposits continues. The role of mining is hard to overestimate. It began to increase with the development of capitalism, especially from the end of the 18th-19th centuries. During this period, mass construction of factories and plants began, production capacities increased, and the consumption of energy and minerals increased. The rapid growth of industry has turned the mining industry into the main material production sector of the world economy. Thanks to it, the state is provided with mineral fuel, ores of nonferrous, ferrous, noble and rare metals, non-metallic raw materials. The mining industry is an indicator of the country's economic potential and development. The extracted mineral

\footnotetext{
* correspondent author: oekalenov@yandex.ru
} 
raw materials provide the productive potential of the state. Society uses its benefits, providing its comfort. Without primary materials and energy resources, other industries could not exist, including the most high-tech ones. Despite the active influence of the transformation processes caused by total digitalization and the formation of a new type of economy, in which information and knowledge play the main role, the mining industry remains one of the leading sectors of the global economy.

The mining industry affects the interests of a large number of entities. These are mining companies themselves, the state that acts as a regulator, investors, contractors and suppliers, service companies, research organizations, and, of course, consumers. Thus, it is advisable to look at the mining industry through the prism of an ecosystem. The application of the ecosystem approach allows the best development of the existing potential of mining enterprises, increase the efficiency of their work, and contributes to the activation of the development and dissemination of innovations in this environment.

\section{Materials and Methods}

Various aspects of innovative development in general, as well as the formation and dissemination of innovations in particular, are widely discussed in the writings of both Russian and foreign researchers, among which are the publications of the following authors: G. Mensch [1], J. Schumpeter [2] , S. Glazyev [3], F. Agafonov [4], O. Borisova [5], T. Skryl [6], A. Kovalev [7] and others. The problems of regional development are considered in the works of A. Balabanova [8], V. Frolova [9], O. Ivanenko [10], M. Anastasova [11]. Various aspects of the formation of business ecosystems were considered by J.F. Moore [12], C. W. Wessner [13], and others.

With its huge raw material, scientific and educational potential, Russia is still far behind the leading countries in the formation of a new type of economy [13]. For the successful integration of our country into the economy of the future, it is necessary to begin this process precisely with the regions as part of the country's territorial economic system. However, not all regions are characterized by an equally high level of innovative technological development and knowledge-intensive processes, which are the "cornerstone" in the formation of a new type of economy. The economy of the mining regions is based, as a rule, on low-tech industries, mainly related to the primary sector of the economy. Therefore, for their successful integration into the new economic realities, special tools are needed, one of which is the ecosystem approach.

Для исследования был выбран ключевой промышленный регион России Кемеровская область. На его долю приходится свыше $50 \%$ добычи угля в стране, значительная часть выплавки чугуна и стали, а также производства готового проката черных металлов. Исходя из этого, проблема формирования инновационной экосистемы тут стоит особенно остро.

For research, a key industrial region of Russia, the Kemerovo Region, was selected. It accounts for over $50 \%$ of coal production in the country, a significant part of the smelting of iron and steel, as well as the production of finished rolled ferrous metals. Based on this, the problem of forming an innovative ecosystem is especially acute here.

\section{Results and Discussion}

In the current economic situation, the transition from a raw material orientation to an innovative high-tech development path is a priority for the Russian economy. Providing conditions for economic development is associated with the formation of an innovative ecosystem. It characterizes the modern model of innovative development of the economy of 
a country, region or industry, being an actual version of earlier concepts, the main of which is the theory of the national innovation system (NIS). The concept of an innovative ecosystem was introduced in 2004 by Charles Wessner, a recognized expert in innovation [8]. The basis of this theory is the presentation of innovation as a process of transforming scientific research into a product or service that is in demand on the market. This transformation requires a large number of joint efforts of all its participants: enterprises, research organizations, universities, investors, venture funds, etc. An innovative ecosystem combines these efforts to achieve a synergistic effect.

An innovation ecosystem combines two main terms: "innovation activity" and "ecosystem".

The concept of the ecosystem was first proposed in 1935 by the English botanist and ecologist Arthur Tensley, who implied a biological system in it, which included a set of living organisms, their living environment and the connections through which their vital activity (exchange of matter or energy) proceeds. Having become one of the basic concepts in ecology, the term later spread to other areas of science, including economics. In the 1990s management expert James F. Moore proposed a concept for strategic planning of a business ecosystem in which he used a number of environmental metaphors to justify the competitiveness and development of companies. Obviously, the ecosystems themselves existed long before that. For example, Ford adhered to an ecosystem approach to its business model at the beginning of the 20th century, as evidenced by the famous phrase of Henry Ford himself: "A car is not a luxury, but a means of transportation," thereby indicating consumer involvement in the process of manufacturing and selling cars [9].

Modern economics identifies several approaches to the definition of the ecosystem, considering one model from different points of view. Firstly, it can be represented as a set of elements (participants) interacting in the process of development, production and marketing of products. It can be suppliers, manufacturers, sales organizations, investors, as well as the buyers themselves. Secondly, this is a digital platform for the interaction of the above participants, allowing the use of a synergistic effect. Finally, the ecosystem is the organization itself, using innovative approaches to management and considering the enterprise as a self-developing living organism that actively interacts with the external environment.

Innovation is understood as an activity related to the transformation of knowledge into new or improved products (services) introduced on the market, into new or improved technological processes or methods of production (transfer) of services used in practice. In this case, the following main areas of innovation can be distinguished:

- conducting basic and applied research;

- development and testing of new products and processes;

- acquisition of know-how, technical information, professional knowledge, etc.;

- investments in innovative equipment;

- staff development and hiring of highly qualified employees.

Thus, an innovation ecosystem should be understood as a self-developing and selfregulatory open system, which includes a set of elements (participants) involved in the development and implementation of innovations and provides conditions (infrastructure) for their effective dissemination. It creates the innovations necessary for society and other industries, which in turn form new demands and are the resource base for the selfdevelopment of this ecosystem. Thus, an innovation ecosystem cannot exist on its own, independent of global economic processes. There is interdependence. The economic system is requesting innovative products and services, and the economy cannot develop without the creative resources of the innovation ecosystem.

The basis of the innovation ecosystem is knowledge that is creatively processed by innovators and embodied in technology, product or services, through the environment - for 
example, technopark structures - is distributed further (Figure 1). New knowledge is the driving force that transforms the state of the economic system, developing it, and makes periodic qualitative transitions. For a long time, the production of knowledge as an innovative process was considered mainly as a phenomenon that relates only to those industries that are characterized by the so-called high technologies, the manufacture of new product samples directly on the basis of specific scientific research and technological developments, technological innovations. However, practice has refuted such a narrow approach to effective management, proving that there can be no industries that do not use new knowledge in the manufacture of products, the provision of services and in the management methods themselves. Thus, the subjects of the innovation ecosystem can be divided into two categories: generators of innovation, i.e. those who are directly involved in their creation, and innovation replicators who help innovators (investors, funds) and create demand for innovations.

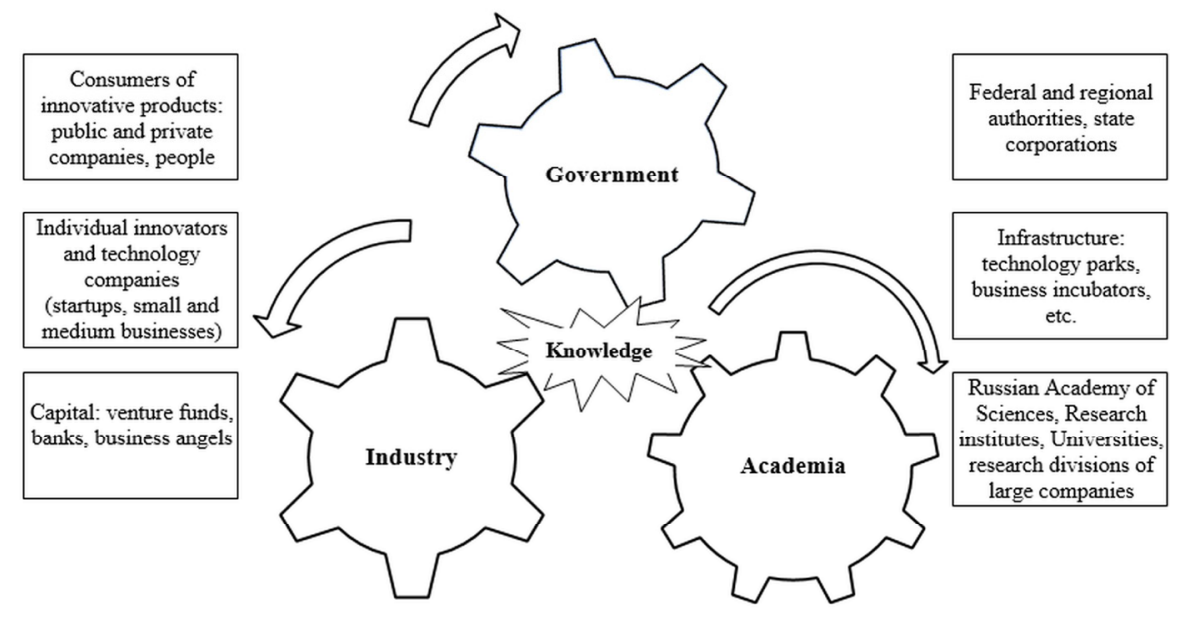

Fig. 1. Key elements of an innovation ecosystem.

Depending on the scale of functioning, it is advisable to distinguish the following levels of innovative ecosystems:

- macro-level. Firstly, it is a global innovation ecosystem, i.e. environment with its inherent participants, in which global innovative projects are implemented to speed up the breakthroughs in recognized areas of knowledge (nano- and biotechnologies, digitalization, energy, etc.). Secondly, the national innovation ecosystem, which implies the totality of the efforts of the state, the activities of business and other organizations of various legal forms and individuals aimed at creating, developing, maintaining, disseminating new knowledge and transforming them into technologies, products (services).

- meso-level: regional and sectoral innovation ecosystems. Regional ecosystems are the basis of national ecosystems and should ensure the implementation of state innovation policy at the regional level. As a rule, industry-specific partnerships are developed on the platform of open innovations, public-private partnerships, the organizations of research activities within corporations and the a network of small innovative enterprises.

- micro-level, i.e. innovative ecosystems of enterprises and organizations, which include the companies themselves and the networks of suppliers, market intermediaries, consumers and competitors they form.

The ecosystem approach considers innovative systems at all levels as a dynamic set of organizations and institutions, along with the diversity of their internal connections. They consist of economic agents, their relationships and an innovative environment that includes ideas, technologies, rules and norms of culture and socio-economic interaction. The triple 
helix model, which is the foundation of an innovative ecosystem, involves the interaction of three elements: production, science, and the state.

According to the design of this model, the mandatory participation of all key partners government, business, the scientific and educational complex, with the possibility of leadership for each of them, especially at the initial stage of the process of creating an innovative economy. The Triple Helix concept provides for gradual innovative development as a result of the constructive interaction of the scientific and educational complex, business and government (at the national and regional levels). Initially, "double spirals" are created, i.e. the interaction between science and business, business and government, etc., which then form the "triple helix".

The model of innovative development of the Triple Helix is characterized by the following:

- strengthening the role of the scientific and educational complex as a leader in relations with business and government;

- the desire for cooperation of all participants in the triad "scientific and educational complex - business - government." Moreover, the innovative component is the result of trilateral interaction, and is not created on the administrative resource of the regional (federal) government;

- expansion of the traditional functions of each of the participants who have to partially take on the role of the other. Institutions capable of performing non-traditional functions are considered the most important source of innovation. It seems that initially the roles of each institution are strictly defined: the role of business in the Triple Helix model is production, government is the source of contractual relations guaranteeing stable interaction, and the scientific and educational complex is a source of knowledge and technology.

In the structure of the gross regional product of the Kemerovo region, the main type of economic activity was mining: $2005-27.1 \%, 2010-31.4 \%, 2015-25.6 \%, 2018-36.6 \%$. The area does not belong to innovative leaders and faces a number of problems in creating, implementing and promoting innovations. At the same time, according to the authors, the main problem of innovative transformations is the lack of infrastructure necessary for technological development, including the provision of interaction between the state, science and business (industrial enterprises).

In Kuzbass, with varying degrees of success, the process of forming "double spirals" of innovative development has been launched:

- scientific and educational complexes - business. This interaction is still underdeveloped and cannot be considered as a coordinated "spiral" of development.

- government - the raw materials industry. The power of the raw material complex enables it to establish trusting relationships with the state block of the "spiral", which is directly involved in the industry's revenues as a co-owner of large business.

- government - the rest of the business. Most enterprises in other industries have not yet overcome stagnation that began at the end of the last century. Those enterprises that are able to enter the innovative market to create import-substituting products, show a demand mainly for imported equipment.

One of the tools for implementing the Triple Helix model should be the main element of the Kemerovo region's innovation infrastructure - the Kuzbass Technopark, located on an area of 23.3 hectares and having the premises of 16.5 thousand $\mathrm{m}^{2}$.

Coal is one of the main energy sources, and its role in the global energy balance will grow. However, Russian coal industry enterprises are in urgent need of modern and innovative technologies at all stages of the technological chain in the coal sector, despite the fact that the development of the coal industry is one of the priorities of the Energy Strategy of the Russian Federation. In 2007, the economy of Kuzbass was booming. Coal industry after structural adjustment of 1990s - early 2000s demonstrated high investment 
activity, energy prices were rising. The level of socio-economic development of the region as a whole allowed the development of large-scale projects in various fields. Innovations were supposed to help the Kemerovo region solve its main tasks - to bring coal enterprises to a new technological level, increase the efficiency of nature management, and minimize the technological impact on the environment. Actually, the profile of the Kuzbass Technopark was determined.

The infrastructure of the technology park includes a center for the collective use of equipment, an engineering center, a production and laboratory building "Ecology and Nature Management", a business incubator, a co-working center, and a center for youth innovative creativity [14]. The "Medicine and Biotechnology" building is under construction. The functions of the Kuzbass Technopark include: research of commodity and commodity markets, search for information about technologies, the provision of infrastructure to accommodate the business, assistance in promoting projects and technologies to target markets, assistance in reducing administrative barriers, mediation in cooperation with state and regulatory bodies, assistance in attracting funding to projects at various stages of implementation, assistance in the implementation of new management technologies that increase the efficiency of project implementation.

The main areas of specialization of the technology park are mining and processing of coal, energy, engineering, processing of ore and non-metallic minerals, medicine, biotechnology, ecology, security, information technology, education. The largest "brainchild" of the Kuzbass Technopark is the global project for the extraction of methane gas from coal seams, which is today an indicator of the level of development of Siberia's innovations. Another major project of residents of the Kuzbass Technopark is the production of heart valve bioprostheses. This product is provided by all regional and federal clinics east of the Urals, as well as many medical institutions in Moscow, St. Petersburg, and the Volga region.

The Kuzbass Technopark promotes the transfer of enterprises of the main industries to a new technological level, increasing the efficiency of environment management and minimizing the technogenic impact on the environment. For the period 2010-2017 The Kuzbass Technopark supported 61 resident companies implementing innovative projects. At the same time, 22 residents were located on the territory of Technopark. During this period, more than 360 applications for support were considered, 174 innovative projects passed the expert council, 53 projects received regional tax benefits. The number of residents in 2016 was 28, including small and medium enterprises - 26. At the same time, the occupancy of the areas was about $34 \%$. In 2018, the situation improved significantly. Therefore, the occupancy of the areas increased to $76 \%$. The number of residents increased by almost 2.5 times and amounted to 68 . The share of small and medium-sized businesses is $94 \%$.

Total investment by resident companies in 2010-2016 amounted to 11 billion rubles, the volume of capital investments -8.7 billion rubles, 1,705 new jobs were created. The total amount of revenue received by residents for the period 2010-2016 amounted to 14.5 billion rubles, the volume of tax deductions from resident companies -2.6 billion rubles. At the same time, in 2016 the residents' revenue amounted to 2.3 billion rubles, the volume of tax deductions -0.420 billion rubles, 1,060 jobs were created.

In 2017, investments in the development of projects of resident companies amounted to 909.2 million rubles, capital investments -573.6 million rubles, revenue -2.16 billion rubles. The number of employees in resident companies is 1061 people. Tax deductions amounted to 585 million rubles. The amount of manufactured products and services by resident companies in cash equivalent was 1.78 million rubles. 
In 2018, residents spent on $R \& D$ amounted to 1 billion rubles, and revenue -2.26 billion rubles. The volume of export of products was equal to 259 million rubles, tax exemptions - 551 million rubles.

The volume of investments made from budget funds of various levels by the cumulative result in 2018 amounted to 999 million rubles. Of these, 492 million rubles - the funds from the federal budget (49\%), 507 million rubles - investments from the regional budget $(51 \%)$.

The main support measures for residents of the Kuzbass Technopark are the reduced income tax rate $(13.5 \%)$ and the complete absence of property tax. However, not only residents are supported, but also management companies, for example, a 5\% tax rate for managing organizations that use a simplified taxation system and choose income reduced by expenses as an object of taxation. Since 2018, the Kuzbass Technopark has been a regional operator of the Skolkovo Foundation. This status allows residents of the technology park to gain access to federal and international services, federal grants and tax benefits, and increases the investment attractiveness of enterprises.

According to the results of the rating carried out by the Association of Clusters and Technology Parks of Russia, the efficiency of the Kuzbass technology park in 2018 is estimated as sufficient and amounts to $82.5 \%$ of the average Russian value.

\section{Conclusion}

Mining industry entering a new, higher level of development, efficiency and productivity involves solving a number of tasks and fulfilling conditions, the main of which are:

- development of partnerships between industry and government, science and education, aimed at the joint solution of pressing problems;

- technical re-equipment, introduction and use of new, more modern, productive, powerful equipment;

- introduction of new technologies in the process of extraction and processing of extracted minerals;

- advanced training of workers and cadres in leading positions at mining enterprises.

It is the application of the ecosystem approach to managing the development of the mining industry, which consists in the formation of an appropriate innovative ecosystem, that can become the most comprehensive and most effective way to resolve these issues. This will fully reveal the huge potential of mining enterprises and harmoniously integrate into a new type of economy.

\section{References}

1. G. Mensch, Stalemate in technology: innovations overcome the depression (Cambridge, Masachusetts, 1979).

2. J. Schumpeter, The theory of economic development (Progress, Moscow, 1982).

3. S. Glazyev, The economic theory of technical development (Science, Moscow, 1990)

4. F. Agafonov, A. Genin, O. Kalinina, O. Brel , O. Zhironkina, E3S Web Conf., 15, 04011 (2017)

5. O. Borisova, V. Frolova, L. Artamonova, E3S Web Conf., 105, 04047 (2019)

6. T. Skryl, E. Shavina, E. Dotsenko, E3S Web Conf., 105, 04049 (2019)

7. O. Miliushenko, A. Kovalev, M. Zhidkova, E3S Web Conf., 105, 04046 (2019)

8. A. Balabanova, V. Balabanov, E. Dotsenko, N. Ezdina, E3S Web Conf., 15, 04013 (2017) 
9. V. Frolova, O. Dolina, T. Shpilkina, E3S Web Conf., 105, 01054 (2019)

10. O. Ivanenko, E3S Web Conf., 105, 04025 (2019)

11. M. Anastasov, N. Kazitskaya, I. Politkovskaya, E3S Web Conf., 105, 04043 (2019)

12. J. F. Moore, The Death of Competition: Leadership and Strategy in the Age of Business Ecosystems (Harper Business, New York, 1996)

13. C. W. Wessner, Entrepreneurship and the Innovation Ecosystem. Policy Lessons from the United States (Linden, Germany, 2004)

14. Association of clusters and technoparks. URL: http://akitrf.ru/ 